\title{
The differences in insulin doses and the risk of hypoglycemia in 2 distinct days in the Romania diabetes futsal team
}

Authors: D.T. Cosma ${ }^{1}$; C.A. Silaghi²,3; H. Silaghi ${ }^{3,4}$; I.A. Veresiu ${ }^{1,3}$

Coordinator: I.A. Veresiu
1 Diabetes, Nutrition and Metabolic diseases Clinical Center, Cluj-Napoca ${ }^{2}$ Endocrinology Clinic

3 "Iuliu Hatieganu" University of Medecine and Pharmacy, Cluj-Napoca

${ }^{4} \mathbf{V}^{\text {th }}$ Department of Surgery

\section{BACKGROUND}

>in type 1 diabetic athletes, the blood glucose (BG) response to physical activity (PA) varies, being influenced by many factors, such as: the type of exercise, the insulin dose administered, the insulin absorption, etc;

$>$ besides interindividual variability, the BG response can be fully or partially reproducible in the same subject;

$>$ avoiding exercise induced-hypoglycemia is one of the most important strategies in order to improve the performance during PA.

\section{INCLUSION CRITERIA}

- age > 18 years old;

- type 1 or type 2 diabetes mellitus (DM);

- members of the Romania diabetes futsal team (DiaRomania);

- $\mathrm{A} 1_{\mathrm{c}} \leq 9.5 \%$

- no other chronic diseases or severe complication of DM in time of enrollment.

\section{MATERIALS AND METHODS}

METHODS
- observational study;
- the assessment $\rightarrow$ self-monitoring diary with
at least 7 BG measurements (including at
least one during the night) and the insulin
doses administered;

\section{RESULTS}

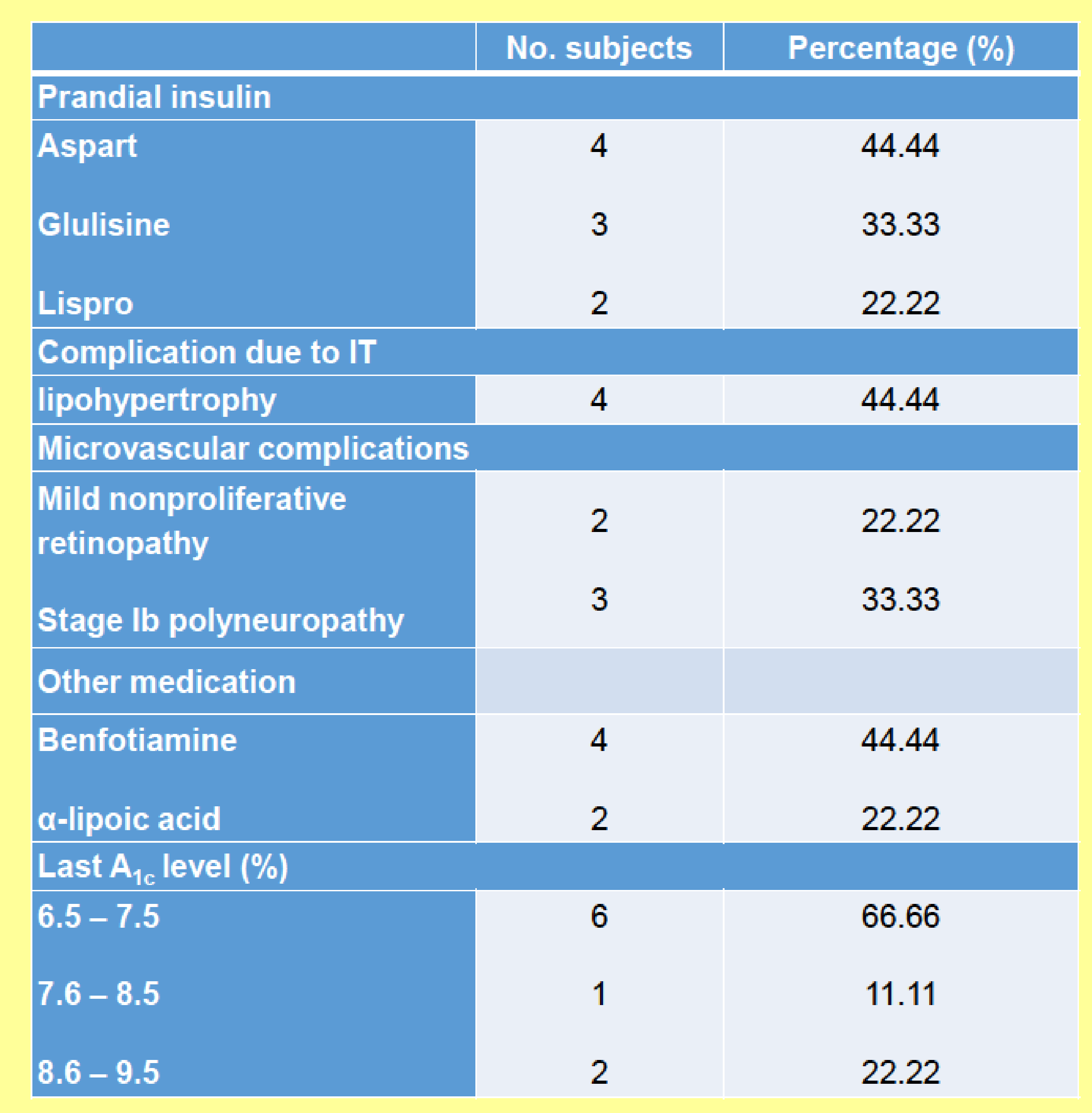

Table no. 2: Clinical characteristics of the players

\section{AIMS}

$>$ to evaluate the demographic and clinical characteristics of the $s$ population;

$>$ to assess the risk of hypoglycemia, the insulin and BG variabilit different days (with and without physical activity);

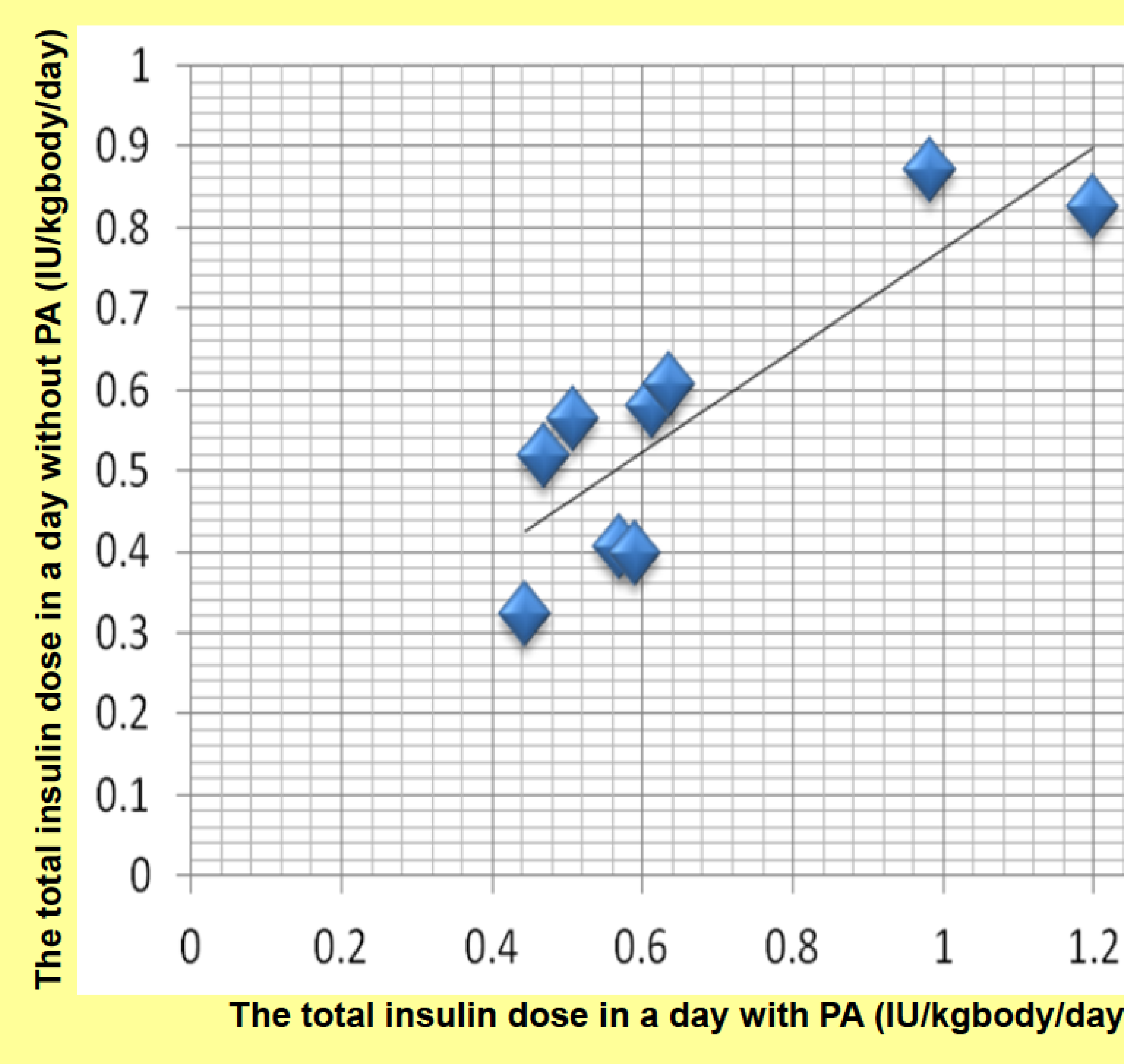

Fig. no. 5: The correlation between the total insulin doses bet'
- Microsoft Excel 2007 and SPSS 17.0

- Pearson coefficient $\rightarrow$ to establish the correlations between the insulin dose respectively the average BG levels;

- Relative risk (RR), attributable risk (A odds ratio (OD) $\rightarrow$ to compare the ris hypoglycemia between the 2 different

\begin{tabular}{|c|c|c|}
\hline & No. subjects & Percentage (\%) \\
\hline Backgrounds & & 88.88 \\
\hline Urban & 8 & 11.11 \\
\hline Countryside & 1 & \\
\hline Age (years) & & 55.55 \\
\hline $20-29$ & 5 & 44.44 \\
$30-39$ & 4 & \\
\hline BMI (kg/m²) & & 66.66 \\
\hline $18.5-24.9$ & 6 & 33.33 \\
\hline $25-29.9$ & 3 & 33.33 \\
\hline Family history (DM) & 3 & 44.44 \\
\hline Type 1 & 4 & \\
Type 2 & & 55.55 \\
\hline Age of DM (years) & 5 & 33.33 \\
\hline $5-10$ & 3 & 11.11 \\
$11-20$ & 1 & \\
\hline $21-30$ & &
\end{tabular}

Table no. 1: General characteristics of the players

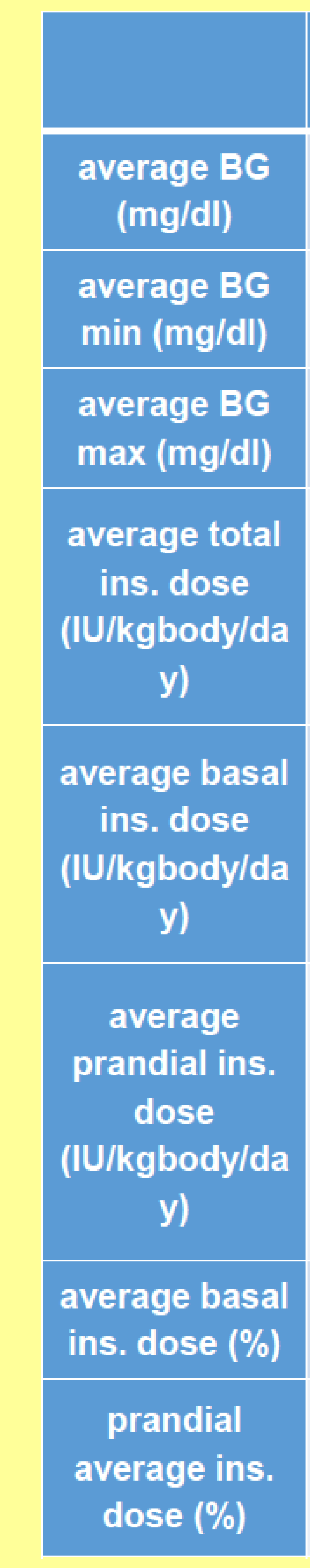

\begin{tabular}{|c|c|c|c|c|}
\hline no PA & with PA & p value & $\begin{array}{c}\text { p statistically } \\
\text { significant }\end{array}$ & $\begin{array}{c}\text { Pearson } \\
\text { coef. }\end{array}$ \\
\hline 135.41 & 147.16 & 0.198 & $<0.01$ & 0.473 \\
\hline 72 & 59.33 & 0.476 & $<0.01$ & -0.274 \\
\hline 228 & 272.77 & 0.767 & $<0.01$ & -0.115 \\
\hline & & & & \\
\hline 0.667 & 0.565 & 0.003 & $<0.01$ & 0.859 \\
\hline
\end{tabular}

Table no. 3: The correlations between the insulin doses and respectively BG variations between the 2 distinct days

\begin{tabular}{|c|c|c|c|}
\hline \multicolumn{4}{|l|}{ Risk Estimate } \\
\hline & \multirow[t]{2}{*}{ Value } & \multicolumn{2}{|c|}{$95 \%$ Confidence Interval } \\
\hline & & Lower & Upper \\
\hline \multirow{4}{*}{$\begin{array}{l}\text { Odds Ratio for } 1 \text { (with } \mathrm{PA} / \mathrm{no} \\
\mathrm{PA} \text { ) } \\
\text { For cohort } 2 \text { =with } \\
\text { hypoglycemia } \\
\text { For cohort } 2 \text { =no hypoglycemia } \\
\mathrm{N} \text { of Valid Cases }\end{array}$} & 4.375 & .564 & 33.949 \\
\hline & 1.750 & .779 & 3.932 \\
\hline & .400 & .103 & 1.550 \\
\hline & 18 & & \\
\hline
\end{tabular}

Table no. 4: Hypoglycemia risk assessment using OR and RR

\section{CONCLUSIONS:}

The physical activity it's an important risk factor for hypoglycemia in type 1 diabetic athletes.

$>$ Although the differences in insulin doses between the 2 days were statistically significant, an increase hypoglycemia was noted, proving the inappropriate reduction in insulin doses and/or carbs intake prior, $c$ after exercise.

$>$ Individualized strategies are needed in order to avoid hypoglycemia and to increase the athlete's perfc 